\title{
Potential Application of Silver Nanoparticles Encapsulated in Branched Amphiphilic Peptide Capsules to Circumvent Antibiotic Resistance in Methicillin-Resistant Staphylococcus Aureus: A Research Protocol
}

Joan Lee, BHSc Student [1], Russell Leong, BHSc Student [1]*, Zejia Chen, BHSc Student [1], Chelsea Zhang, BHSc Student [1]

All authors contributed equally.

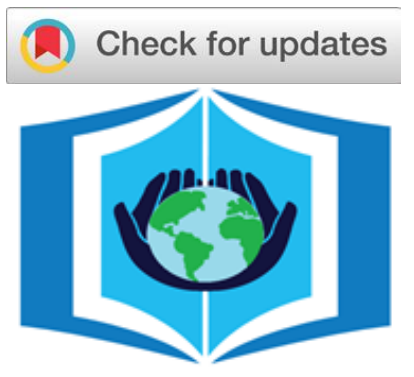

[1] Faculty of Health Sciences, McMaster University, Hamilton, Ontario, Canada, L8S 4L9

*Corresponding Author: leongr2@mcmaster.ca

Note: Correction added after original version published on October 5, 2020. We regret any inconvenience caused.

\begin{abstract}
Introduction: Antibiotic resistance is a major global health concern as many fatalities occur each year due to severe infections associated with it, such as sepsis. This research protocol hopes to address the issue of antibiotic resistance in methicillin-resistant Staphylococcus aureus (MRSA) by using an alternative antibiotic therapy. Silver nanoparticles (AgNPs), which have antibiotic properties and low antibiotic resistance potential, will be administered in conjunction with stable and biocompatible branched amphiphilic peptide capsules (BAPCs). Surface functionalized ligands will be attached to the peptide capsules to target iron receptors essential to MRSA survival. By targeting its iron receptors, the bacteria will be unable to mutate in such a way that would attenuate its uptake of this antibiotic.

Methods: Testing will begin in vitro on MRSA cultures to assess the minimum inhibitory concentration of the various AgNP treatment groups. Constraints determining the minimum inhibitory concentration include a minimum 3-hour delay in bactericidal effect from application, and a $95 \%$ eradication efficacy. Drug efficacy will be evaluated via ex vivo and in vivo mice experiments, with off-target toxicity effects measured via BAPC targeted immunohistochemistry, and both serological and organ-based tests. Repeated in vivo treatments will be performed against a control to measure the relative antibiotic resistance advantages this treatment proposes. As this protocol requires the use of mice, ethics approval from the Canadian Council on Animal Care will be obtained prior to experimentation.

Results: It is expected that the AgNPs will be successfully encapsulated within the structurally-sound BAPCs and that the AgNPs will eradicate a significant amount of the MRSA present in the human body with minimal side effects. The in vitro, ex vivo and in vivo tests are likely to yield results that demonstrate that the most effective protocol in eradicating MRSA is to use AgNPs in BAPCs in conjunction with a vancomycin treatment. The proposal will likely satisfy the criteria for appropriate AgNP doses, which includes bactericidal effect in a time frame of hours, over 95\% efficacy, and statistically significant reproducibility.

Discussion: Successful BAPC mediated delivery of AgNPs prove the potential for targeted antibiotic application against multidrug bacteria with lower risk of antibiotic resistance compared to conventional antibiotics. This proof of concept protocol demonstrates the potential for applying rational design of BAPCs as a delivery vector. Certain limitations, including off-target toxicity and redundant targeting are issues to be cognizant of and controlled.

Conclusion: This novel therapy can be considered as a preliminary step in overcoming antibiotic resistance. With appropriate modifications to the functional ligands attached to the BAPCs, the proposed drug mechanism could be applied to treat other bacterial strains.
\end{abstract}

Keywords: antibiotics; antibiotic resistance; methicillin-resistant Staphylococcus aureus; silver nanoparticles; branched amphiphilic peptide capsules; targeted therapy; nanomedicine; nanotechnology; microbiology 
UNDERGRADUATE RESEARCH IN NATURAL AND CLINICAL SCIENCE AND TECHNOLOGY (URNCST) JOURNAL Read more URNCST Journal articles and submit your own today at: https://www.urncst.com

\section{Introduction}

Antibiotics are organic molecules capable of inhibiting or killing microbes through interactions specific to bacterial targets [1]. The first antibiotic was discovered in 1928, and they have since transformed modern medicine, saving millions of lives [2]. However, resistance has also since been developed against nearly all invented antibiotics. Antibiotic resistance has been declared one of the world's most pressing global health concerns, with more than 35,000 people dying each year in the United States due to antibiotic-resistant infection [3]. Due to the misuse of antibiotics, bacteria such as methicillin-resistant Staphylococcus aureus (MRSA) have seen an increase in antibiotic resistance over the past years to the point of being resistant to common antibiotics [4]. One of the causes of this increase in antibiotic resistance is the over-prescription or misuse of antibiotics. Misuse of antibiotics can serve as a driving force for resistance evolution, as the antibiotics do not stop the bacteria's reproduction while also removing drug-sensitive competitors. Consequently, resistant bacteria have the opportunity to reproduce and thrive due to less competition [5]. New antibiotic-resistant mechanisms in MRSA can lead to higher medical costs and prolonged hospital stays, in addition to reducing our ability to overcome other common infectious diseases [6]. In serious cases, MRSA can lead to severe conditions such as sepsis or necrotizing pneumonia [6].

For the past few decades, vancomycin has been the treatment of choice for MRSA [7]. However, since its introduction, there have been increasing reports of treatment failure and growing concerns of reduced vancomycin efficacy [8]. With the recent emergence of vancomycin-resistant Staphylococcus aureus, development of alternative treatment options is critical. A wide range of novel therapies are currently being engineered to target antibiotic resistant bacteria [9]. Although principles of targeted therapy are studied, its potential for application in bacterial resistance is vast and in need of further study. In this paper, we investigate the possibility of using an alternative targeted therapy to circumvent antibiotic resistance in MRSA.

Silver nanoparticles (AgNPs) have proven to be effective as antibiotics with low potential for eventual antibiotic resistance [10]. They act as antibiotics by interacting with cellular structures, such as ribosomes, to cause bacterial dysfunction [11]. Additionally, they also produce high levels of reactive oxygen species (ROS) which inhibits respiration and growth of cells, leading to apoptosis [11]. When AgNPs first take action, its conversion into silver ions enhances its cytotoxic properties [12]. However, after interacting with other ions and proteins in the cell for 3 hours, its toxicity is eliminated [12]. Non-toxic silver ions which are not within a branched amphiphilic peptide capsule (BAPC) or MRSA will eventually be cleared away by macrophages [13].

Leong et al. | URNCST Journal (2020): Volume 4, Issue 9

DOI Link: https://doi.org/10.26685/urncst.198
BAPCs are stable, biocompatible peptide capsules that can encapsulate a variety of substances including nanoparticles [14]. They display increased specificity, biodegradability, circulating time, and tunability over lipid vesicles [14]. Flexible in nature, BAPCs can be resized between 6-2000 nm with appropriate temperature manipulations [15-16]. BAPCs are created through the selfassembly of two large main branched peptides, which can be enhanced to include various surface proteins [17]. Using these surface functionalization ligands, BAPCs are capable of targeting specific receptors on specific cells.

Due to iron's role as a critical cofactor for many different biochemical pathways, MRSA requires it for various growth and developmental processes. MRSA accesses iron through the uptake of heme and siderophores [18-19]. In particular, the receptors involved in heme uptake are IsdA, IsdB, IsdC, and IsdH [18]. Common ligands for these receptors include heme, hemoglobin and haptoglobin-hemoglobin. MRSA can also obtain iron through siderophore uptake, which involves the receptors HtsA, SirA, and CntA, with their ligands being staphyloferrin A, staphyloferrin B, and staphylopine respectively [19]. These iron uptake mechanisms are unique to MRSA, as human cells mainly use the transferrin receptors TfR1 and TfR2 [20].

This protocol aims to address the issue of antibiotic resistance in MRSA using AgNPs in conjunction with BAPCs as an alternative targeted antibiotic therapy.

\section{Hypothesis}

In this paper, the targeted therapeutic potential of using AgNPs as an alternative antibiotic by mitigating its toxicity through storage in BAPCs is explored.

To ensure target specificity and to contain the mammalian toxicity of AgNPs, a select concentration of AgNPs will be encapsulated within BAPCs [14]. The peptide capsids will be engineered with iron surface functionalization ligands: heme, hemoglobin, staphyloferrin A, staphyloferrin B, and staphylopine, to target the main siderophore and heme uptake receptors on MRSA: IsdA, IsdB, IsdC, HtsA, SirA and CntA [17-18, 21]. In practice, this will reduce the likelihood of a resistance mechanism being developed by MRSA because any functional modifications to the iron receptors would attenuate essential iron uptake, leading to cellular death and dysfunction.

Should this treatment be approved, BAPCs containing AgNPs will be administered intravenously in a saline solution. In the blood, BAPCs will be able to selectively target colonies of MRSA present in the body using its functional ligands. After being actively transported into the MRSA by the respective receptors, the new $\mathrm{pH}$ of the perinuclear cytosol will lead to a reduction of electrostatic attraction in the BAPC, releasing the AgNPs [15]. The released AgNPs will create ROS and hydroxyl radicals that stimulate the activation of the apoptosis pathway [11]. The toxicity of AgNPs will be neutralized through interactions 
UNDERGRADUATE RESEARCH IN NATURAL AND CLINICAL SCIENCE AND TECHNOLOGY (URNCST) JOURNAL Read more URNCST Journal articles and submit your own today at: https://www.urncst.com

with cellular proteins and ions over a time frame estimated to be 3 hours [12]. After the MRSA's death, it will lyse and release the non-toxic silver particles into the body, which will be taken up by macrophages and other natural host clearance mechanisms [13]. By encapsulating an appropriate dose of AgNPs within peptides, and by timing the death of MRSA until after the silver ions have aged and become non-toxic, the host organism will be protected from silver toxicity at all stages of treatment [12].

\section{Methods}

Ethics Approval

Ethics approval for this study will be obtained through Hamilton's Integrated Research Ethics Board (HiREB). This study will be considered a student project which will take place at McMaster University, and a general research application form will be submitted. All authors on this manuscript will act as co-investigators for the study. Additionally, as a study that involves mice, ethics approval from the Canadian Council on Animal Care will be obtained prior to experimentation. Lastly, for ethical considerations, no in vivo testing will be performed unless ex vivo results are confirmed as successful.

\section{Synthesis and Encapsulation of Silver Nanoparticles}

AgNPs will be formulated through classic chemical reduction using sodium borohydride [22]. First, $0.2 \mathrm{~g}$ of sodium citrate will be added to $75 \mathrm{~mL}$ of deionized water at $70{ }^{\circ} \mathrm{C}$. After, $2 \mathrm{~mL}$ of $1 \%$ weight/volume silver nitrate and $2 \mathrm{~mL}$ of $0.1 \%$ weight/volume of sodium borohydride solution will be added dropwise [22]. The product, a yellowish brown solution, will be stirred at $70{ }^{\circ} \mathrm{C}$ for 1 hour [22]. Removal of excess sodium borohydride will be performed using dialysis against distilled water for 24 hours using cellulose membranes [22]. Finally, $0.02 \mathrm{~g}$ sodium citrate will be used to stabilize the AgNPs [22]. AgNP size in this proposal is standardized to $1 \mathrm{~nm}$ in diameter, as smaller nanoparticles have been shown to display greater antimicrobial activity [23]. The AgNPs will also be spherical-shaped for stronger antibacterial abilities [24].

AgNP encapsulation is planned to occur during natural BAPC self-assembly. Bis(FLIVI)-K-KKKK and bis(FLIVIGSII)-K-KKKK represent the two branched polymers which form the capsule, and will be dissolved in neat 2,2,2-Trifluoroethanol to achieve a fixed final calculation of $0.1 \mathrm{mM}$ [25]. In this solvent, the polymers are helical and facilitate BAPC formation. Formed capsules will be dried in vacuo, and rehydrated with varying buffers containing concentrations of AgNP solution for encapsulation [16].

The MRSA-specific iron receptors are targeted by attaching functional ligands replicated from heme and siderophore mediators to the surface of BAPCs. Ligands can be attached to the surface of BAPCs through careful selection of chemical interactions between reactive groups on the peptide surface and groups present on the ligand [17]. In particular, hydrogen bonding can be facilitated between serine amino acids on BAPCs and hydroxylated iron ligands [26].

\section{Experimental Groups}

Testing of the AgNP treatment aims to validate its potency and relative efficacy compared to standard antibiotic therapy, and assess its off-target toxicity levels and antibiotic resistance potential.

The tests will utilize combinations of the following six different experimental groups (Figure 1). The first group will not receive any treatment, serving as a no-treatment control group. The second group will receive vancomycin as a positive control, to ensure ordinarity of the bacteria strain used and serve as a baseline for efficacy. The third group will serve as a negative control, receiving the empty BAPC to ensure no toxicity exists without AgNP treatment. The remaining three groups will receive separate treatments delivered via BAPCs: vancomycin alone, AgNPs alone, and a mixture of AgNPs and vancomycin in a 1:2 ratio, a combination shown to be more effective than antibiotics alone in previous studies [27]. To ensure reproducibility, tests will be repeated three times. The type of experimental models will vary according to the test being conducted.

\section{In Vitro Preparation}

Determination of required potency and measurement of efficacy will involve in vitro preparations. Using aseptic technique, a small amount of MRSA from acquired frozen stock will be streaked with a sterile wooden applicator onto a small section $(\sim 1 / 4)$ of a Müller-Hinton agar plate [28]. This process is repeated for the other remaining quadrants of the plate. The plates will then be incubated at $37{ }^{\circ} \mathrm{C}$ for 16 to 24 hours [28]. 24 cultures will be prepared; 6 for potency and 18 for efficacy tests.

Determination of Required Potency of Treatment and Measurement of Treatment Efficacy

To evaluate AgNP potency - the specific concentration of AgNPs required to eradicate the entire MRSA population - two groups of MRSA strains will receive different bactericidal treatments (AgNPs alone, and AgNPs $\&$ vancomycin) [29]. From previous studies, the minimum bactericidal concentration of AgNPs for MRSA has been determined to be $64 \mu \mathrm{g} / \mathrm{mL}$, and this will serve as the baseline starting concentration applied in treatment groups for cultures [30]. Flow cytometry will be used to count the number of surviving bacteria following application of the LIVE/DEAD BacLight Viability kit (ThermoFisher). To account for neutralization of the toxic silver particles, MRSA endurance will be measured at different time frames of 30 minutes, 1 hour, 3 hours, and 4 hours after application of treatments. These groups will be evaluated in comparison to a no-treatment control at the same time 
intervals to study relative treatment potency. Based on observation of baseline MRSA concentration posttreatment, the concentration will be varied to find the minimum bactericidal concentration of AgNPs at the 3-hour time frame target. These initial tests will be performed on trial-and-error cultures. Once an appropriate concentration is found, reproducibility testing will be performed to validate the findings.

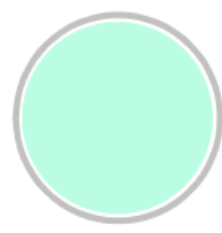

No Treatment Control

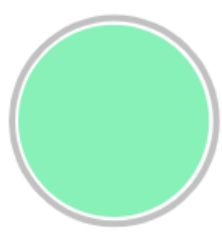

Vancomycin Pos. Control

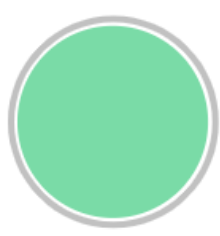

BAPCs Neg. Control

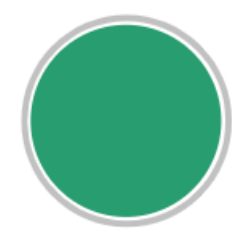

BAPCs + Vanc. Treatment 1
Next, to evaluate treatment efficacy - the number of MRSA eradicated in relation to a specific dose of the treatment - eighteen sample cultures of MRSA strains will be plated on Müller-Hinton agar, separated into three cultures of the above six groups (Figure 1) to ensure reproducibility [29]. Treatment will be measured in the same time intervals as previously described to control toxicity. Efficacy can be measured through flow cytometry, similar to the experiment above.

Figure 1: In vitro procedural testing of various treatment groups to determine the most effective treatment. Testing of the efficacy of BAPCs and AgNPs are compared to no-treatment, positive and negative controls for future ex vivo and in vivo experiments. Testing will be conducted on cultured strains of MRSA.

\section{$\underline{\text { In Vivo and Ex Vivo Preparation }}$}

Ex vivo experiments will be performed to test for offtarget toxicity levels and antibiotic resistance potential, while organ toxicity tests will be conducted in vivo. 10month-old healthy mice of the C57BL/6 strain, with body weight of 30 to $40 \mathrm{~g}$, will be employed in the experiments. The mice will be housed individually within polypropylene cages with stainless steel grills for a period of 5 days in a controlled environment [31]. Temperature will be standardized to $22 \pm 3{ }^{\circ} \mathrm{C}$ with relative humidity of $30 \%$ to $70 \%$, and a 12-hour light and 12-hour dark cycle will be fixed [31]. Water and rodent pellets will be supplied throughout the period of study.

After acclimatizing to the environment, the mice will be given a MRSA adjuvant via intraperitoneal route. The MRSA adjuvant is prepared with $1.2 \times 109 \mathrm{CFU} / \mathrm{ml}$ MRSA culture suspended in $5 \%$ mucin of equal volume [31]. Experimental testing will begin only after 24 hours of MRSA incubation. 54 mice will be used in this study; 18 for each test. Lung tissue will be excised and perfused in an organ bath for ex vivo experimentation.

\section{Treatment Toxicity Testing}

Testing for off-target toxicity levels and antibiotic resistance will be conducted via ex vivo experimentation to mimic mammalian systems. It was previously noted that serious MRSA infections primarily affect the lungs. Thus, lung tissue from mouse models infected by MRSA will be perfused and isolated for this purpose [18]. Treatment will be administered with organ baths, using the same six treatment groups. For identification purposes, BAPCs will be tagged with the exclusively human MUC1 mucin protein [32]. To quantify off-target effects, immunohistochemistry can be used to fluorescently label off-target BAPCs using MUC1, identifying the number of BAPCs endocytosed by non-target cells via microscopy.

Next, toxicity levels of the six groups will be assessed through in vivo experimentation to ensure that the mice and their organs are still functional and not damaged (Figure 2A). Three main tests will be performed, namely a blood analysis, urinalysis and an organ analysis (Figure 2B and C). The blood analysis has two components: a hematological and a biochemistry analysis. Both will be performed on the 14th day following a 12 hour fast [31]. The urinalysis is performed to test the presence of metabolites that resulted from vancomycin degradation [33]. This will be followed by an organ analysis in which the ratio of the weight of each organ to its respective body weight are compared among the six groups. A macroscopic evaluation of each organ will also be analyzed [31].

\section{Antibiotic Resistance Testing}

Relative antibiotic-resistant effects can be determined by measuring the persistence of MRSA in the lungs after the first, third, sixth, and ninth antibiotic applications (Figure 2D). Ex vivo lung tissue will be harvested and plated, and Gram stain in addition to microscopy counts will be used to quantify the amount of living bacteria remaining. 
UNDERGRADUATE RESEARCH IN NATURAL AND CLINICAL SCIENCE AND TECHNOLOGY (URNCST) JOURNAL Read more URNCST Journal articles and submit your own today at: https://www.urncst.com

A control for each lung will be set to ensure that bacterial death can be attributed to the antibiotic application, meaning that bacteria survival is indicative of drug-tolerant mutations.

A
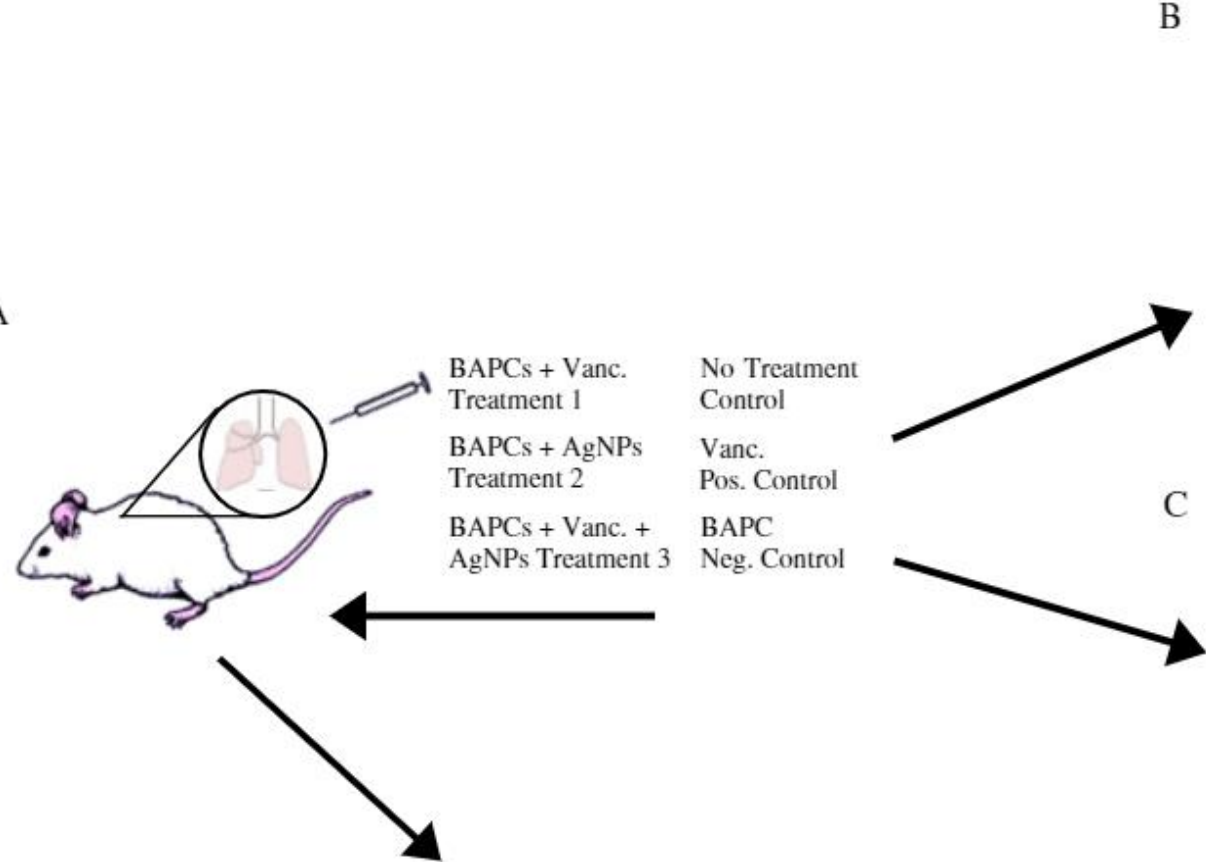

Blood and Organ Testing

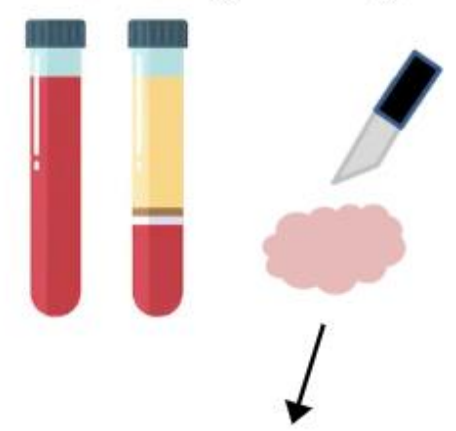

Vanc.

Pos. Control

BAPC

C Immunohistochemistry
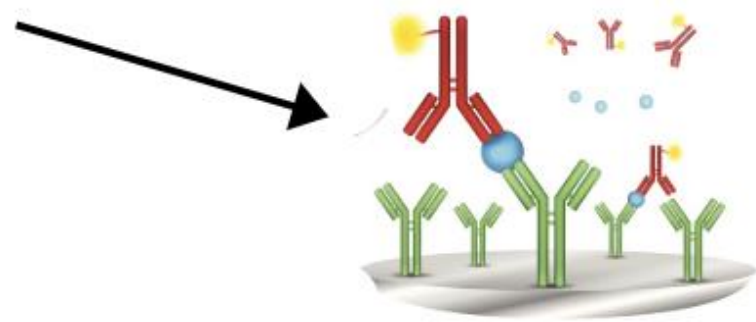

D Antibiotic Resistance Testing via Haemocytometry
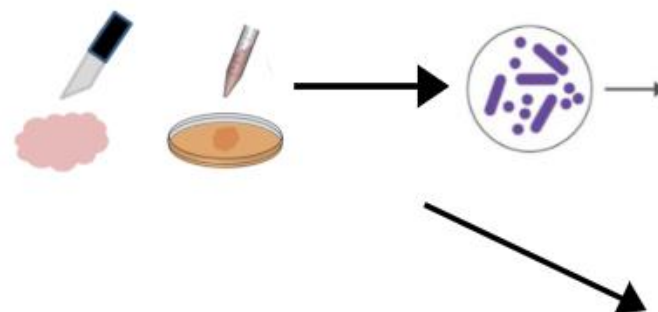

E Urine Analysis

Figure 2: In vivo and ex vivo testing of off-target effects and antibiotic resistance. (A) Mice infected with MRSA will be treated in six groups and investigated after excision of the lungs and comparing the lung-body weight ratio to acceptable ranges as stated in the literature. (B) Silver concentration in the blood will be measured, vancomycin metabolites will be tested for in urine, and organs will be harvested in vivo to test for toxic off-site effects. (C) The number of non-target cells containing MUC1 can be quantified via immunohistochemistry to measure the off-target effects that exist. (D) Antibiotic resistance can be measured by bacterial growth levels after tissue samples were cultured following designated, fixed numbers of treatments.

\section{Results}

It is expected that the AgNPs will be successfully encapsulated within the BAPC, which would be formulated with the appropriate surface ligands [22]. The BAPC would maintain its structural integrity as it travels through the bloodstream. It is predicted that the AgNPs will eradicate a significant amount of the MRSA present in the human body with minimal side effects. Preliminary steps include the determination of suitable AgNP minimum inhibitory concentration (MIC). Criteria for appropriate AgNP doses include: bactericidal effect in a time frame of hours, over 95\% efficacy, and statistically significant reproducibility. Given that previous studies have demonstrated that the minimum bactericidal concentration of AgNPs for MRSA 
UNDERGRADUATE RESEARCH IN NATURAL AND CLINICAL SCIENCE AND TECHNOLOGY (URNCST) JOURNAL Read more URNCST Journal articles and submit your own today at: https://www.urncst.com

is $64 \mu \mathrm{g} / \mathrm{mL}$, the expected concentration of AgNPs needed for the proposal is around $64 \mu \mathrm{g} / \mathrm{mL}$ [30]. AgNP dosage will be used and adjusted while testing ex vivo and in vivo.

For the experimental groups created, it is predicted that the first group (no treatment control) and the third group (treated with empty BAPCs) will yield no changes to the amount of MRSA present. The treatments given to the second group (vancomycin treatment only) and fourth group (treated with vancomycin in BAPCs) are expected to kill most of the present MRSA. Vancomycin has previously been shown to have $77 \%$ efficacy; out of 35 cases, 23 were cured for MRSA while 12 were not [35]. Lastly, it is predicted that the fifth group treatment (AgNPs in BAPCs) will kill most to all MRSA and the sixth group treatment (AgNPs \& vancomycin in BAPCs) will kill all MRSA present.

Initial safety experiments will be conducted in lung tissue. The results of the treatment toxicity testing in both ex vivo and in vivo settings are expected to yield results to a similar degree of effectiveness as in vitro assays. Mice will be followed for response to conventional antibiotics, additional treatment, and antibiotic resistance. In vivo toxicity concerns must also be reviewed as outlined in the experimentation and guidelines cited above. The blood analysis should show the absence of AgNPs, vancomycin or BAPCs. The urinalysis should display results that indicate the presence of metabolites from vancomycin degradation in the groups that include a vancomycin treatment [33]. The organ analysis should display the presence of MRSA from the first and third groups, little MRSA presence from the second and fourth groups, little to no MRSA presence from the fifth group, and the complete absence of MRSA from the sixth group. Immunohistochemistry is predicted to show little to no BAPCs endocytosed by non-target cells. A preliminarily defined ratio of $5 \%$ off-target toxicity, measured by flow cytometry distribution of non-eradicated BAPC compared to total delivered, would be necessary. As well, no evidence of antibiotic resistance should be observed, as quantitatively measured through guidelines cited [34]. Positive results in each phase of testing will indicate successful therapy and potential advancement to clinical trials.

To achieve these results, the study will follow a timeline. Due to COVID-19 concerns, actual experimentation is assumed to begin in 4 months due to the closure of laboratories.

It is hoped that initial ex vivo results will be complete in a year with full results finalized and reported. It is planned upon in vivo testing of this treatment that results will be compared to the previously published toxicological profiles of current distributed antibiotics of varying strength, assessing its ability to meet FDA standards.

\section{Discussion}

This research protocol proposes a method to validate the alternative antibiotic therapy suggested. By assessing the potency, efficacy, toxicity and antibiotic resistant capability of this antibiotic alternative, its viability as a treatment can be determined. Identifying the adequate concentration and size of AgNPs and BAPCs will provide novel insight into the feasibility of administering this treatment.

Results will be analyzed as stated in the methodology. Successful treatment will be defined as the ability of the drug to eliminate the majority of MRSA colonies within a 3-hour time period with minimal adverse effects on the host. The drug's ability to evade antibiotic resistance will be deemed successful if MRSA are unable to successfully mutate by the ninth antibiotic application. Reproducibility of results will suggest the consistency needed to ensure drug reliability. Should animal studies prove to be successful, this drug would proceed to phase one of clinical testing.

Expected results are divided into three main areas of discussion. The first section examines ideal results in the antibiotic activity of the BAPC-AgNP treatment. The second section focuses on the implications of off-target toxicity in vivo. The third section discusses the treatment and its potential to decrease rates of antibiotic resistance conferral.

Ideal results in the efficacy of this proposed treatment would result in significant reproducibility as well as over $95 \%$ efficacy in bactericidal activity. While this expected result can be reasonably achieved in vitro, for ex vivo and in vivo experiments, a decrease in efficacy is to be expected. Vancomycin has been previously reported to have a $77 \%$ efficacy [35] and when using vancomycin with a MIC value of less than $0.5 \mu \mathrm{g} / \mathrm{mL}$, a $55.6 \%$ clinical success rate was observed in treating bacteremia [36]. Vancomycin has been a cornerstone of MRSA therapy since the 1980s; achievement of higher efficacy and success has major implications for alternative antibiotic therapies [37].

Excessive doses of silver nanoparticles have been previously demonstrated in mice to induce hematological and liver enzyme activity changes as well as result in an increase of silver accumulation in brain, lung, liver, testis, and kidney tissue [38]. While it is expected low doses of silver nanoparticles in the range between $60-200 \mu \mathrm{g} / \mathrm{mL}$ will be suitable for in vitro and ex vivo treatments, likely a higher dosage will be required to circumvent in vivo pharmacokinetics. Off-target AgNP treatments in excess of $10 \mathrm{mg} / \mathrm{kg}$ have been shown to impact rats, increasing toxicity levels. [39] Evidence of AgNPs in hematological tests greater than this bound indicate significant ethical consideration is required to further pursue research and development. Discovery of BAPCs and/or vancomycin in the bloodstream would similarly raise concern, although safe vancomycin dosage levels are well established and are not expected to be of concern.

Silver nanoparticles have also been shown to work effectively against multidrug resistance bacteria, and as applied against MRSA in this proof of concept protocol, can function against other bacteria as well [40]. Similarly, silver nanoparticle antibiotic therapy has been shown in 
UNDERGRADUATE RESEARCH IN NATURAL AND CLINICAL SCIENCE AND TECHNOLOGY (URNCST) JOURNAL Read more URNCST Journal articles and submit your own today at: https://www.urncst.com

vitro to not confer antibiotic resistance in multidrug resistant $\mathrm{S}$. aureus and $\mathrm{A}$. baumanii, compared to ciprofloxacin, highlighting a potential decreased risk of this treatment for antibiotic resistance [10]. Negative antibiotic resistance test results from this protocol furthers evidence of the non-resistance conferring capabilities of silver nanoparticles and show its uses as a capable antibiotic.

To our knowledge, having successful drug testing would result in the first demonstrations of the potential of BAPCs with silver nanoparticles as an antibiotic. Targeting different redundant cell surface receptors of bacterial iron uptake redundant pathways with ligands in the BAPC allows us to demonstrate the potential of BAPCs as a rapidly redesignable tool relative to conventional antibiotics to target specific bacterial features. The ability to control which bacteria are affected by the antibiotic, potential for rapid, rational design, as well as stability and biocompatibility within the body, highlight the advantages of BAPC mediated delivery as opposed to common antibiotics and common alternative therapies such as phage therapy.

There are some possible limitations in this treatment, including target specificity and off-site toxicity. While our treatment aims to target the majority of iron receptors on MRSA, there are still some less commonly used methods of iron uptake that cannot be targeted. For example, xenosiderophore receptors FhuD1 and FhuD2 are difficult to target, as they have a wide range of siderophore ligands that could potentially target other beneficial bacteria too [41]. As well, the hemoglobin-haptoglobin receptor, IsdH, cannot be easily targeted as the ligand hemoglobin-haptoglobin is also taken up by monocytes and macrophages [41]. Despite this, it is expected that targeting the main methods of iron uptake will be sufficient to eradicate the bacteria as previous studies have found hemoglobin and siderophore uptake to be vital to MRSA growth [42].

Even though efforts are being made to minimize the toxicity of silver within the human body, it might be a challenge to ensure that MRSA are being consistently eliminated by the recommended period of 3 hours [12]. Should MRSA die prior to 3 hours, the released silver ions may cause toxic side effects. Additionally, previous studies have found that clearance of AgNPs can take more than 56 days [13]. As a result, it is possible that AgNPs that have not been cleared away could accumulate within the body. Through further testing and adjustment of the amount of AgNPs used, toxicity will be minimized. Despite these limitations, it is expected that the advantages to this proposed treatment, such as the facilitated target selectivity, will ultimately outweigh the negative complications.

\section{Conclusion}

The main intent of this research protocol is to propose an alternative antibiotic through the joint use of AgNPs with surface functionalization of BAPCs to facilitate MRSA target selectivity. The potential application of AgNPs in patients with MRSA infections can significantly reduce the current use of antibiotics and subsequently limit future development of antibiotic resistance. This novel therapy can be considered as a preliminary step in overcoming antibiotic resistance, and the theory behind this proposed drug mechanism could be applied to other bacterial strains, with appropriate modifications to the functional ligands attached to BAPCs. Future studies could further explore the viability of this treatment for other bacterial strains.

\section{List of Abbreviations Used}

MRSA: methicillin-resistant Staphylococcus aureus AgNP: silver nanoparticle

BAPC: branched amphiphilic peptide capsule

ROS: reactive oxygen species

MIC: minimum inhibitory concentration

\section{Conflicts of Interest}

The authors declare that they have no conflict of interests.

\section{Ethics Approval and/or Participant Consent}

This research protocol did not require ethics approval and/or participant consent. No live participants were used, and no experiments were conducted for this proposal. For the actual study, ethics approval will be obtained from Hamilton's Integrated Research Ethics Board as well as the Canadian Council on Animal Care prior to experimentation. The authors have acknowledged that ethics approval will be sought after should this protocol be published.

\section{Author's Contributions}

JL: Contributed to the design of the study, drafted the manuscript, revised the manuscript critically, and gave final approval of the version to be published.

RL: Contributed to the design of the study, drafted the manuscript, revised the manuscript critically, and gave final approval of the version to be published.

ZC: Contributed to the design of the study, drafted the manuscript and created all figures, revised the manuscript critically, and gave final approval of the version to be published.

CZ: Contributed to the design of the study, drafted the manuscript, revised the manuscript critically, and gave final approval of the version to be published.

\section{Acknowledgments}

We would like to thank Scinapse McMaster for providing us with the opportunity to participate in the Scinapse 2019-2020 Undergraduate Science Case Competition.

\section{Funding}

This study was not funded.

\section{References}

[1] Davies J, Davies D. Origins and Evolution of Antibiotic Resistance. Microbiology and Molecular 
UNDERGRADUATE RESEARCH IN NATURAL AND CLINICAL SCIENCE AND TECHNOLOGY (URNCST) JOURNAL

Read more URNCST Journal articles and submit your own today at: https://www.urncst.com

Biology Reviews. 2010Sep;74(3):417-33. https://doi.org/ 10.1128/MMBR.00016-10

[2] Ventola C. The Antibiotic Resistance Crisis Part 1: Causes and Threats. Pharmacy and Therapeutics. 2015Apr;40(4):277-83.

[3] Antibiotic / Antimicrobial Resistance [Internet]. Centers for Disease Control and Prevention. 2019 [cited 2019Nov20]. Available from: https://www.cdc.gov/ drugresistance/index.html

[4] Thompson GE, O'Brien B, Husney A, O'Young T, Russo ET. Methicillin-Resistant Staphylococcus Aureus (MRSA) [Internet]. HealthLink BC. 2018 [cited 2019Nov20]. Available from: https://www.healthlinkbc .ca/health-topics/tp23379spec

[5] Aslam B, Wang W, Arshad M, Khurshid M, Muzammil $\mathrm{S}$, Rasool M, et al. Antibiotic resistance: a rundown of a global crisis. Infection and Drug Resistance. 2018May;2018(11):1645-1658. https://doi.org/10.2147/ IDR.S173867

[6] Waness A. Revisiting Methicillin-Resistant Staphylococcus aureus Infections. Journal of Global Infectious Diseases. 2010Jan;2(1):49-56. https://doi.org/ 10.4103/0974-777X.59251

[7] Choo EJ, Chambers HF. Treatment of MethicillinResistant Staphylococcus aureus Bacteremia. Infection \& Chemotherapy. 2016Dec;48(4):267-73. https://doi.org/ 10.3947/ic.2016.48.4.267

[8] Hal SJ, Fowler VG. Is It Time to Replace Vancomycin in the Treatment of Methicillin-Resistant Staphylococcus aureus Infections? Clinical Infectious Diseases. 2013Mar;56(12):1779-88. https://doi.org/ 10.1093/cid/cit178

[9] Kotil S, Jakobsson E. Rationally designing antisense therapy to keep up with evolving bacterial resistance. Plos One. 2019Jan;14(1):e0209894. https://doi.org/ 10.1371/journal.pone.0209894

[10] Ellis DH, Maurer-Gardner EI, Sulentic CEW, Hussain SM. Silver nanoparticle antibacterial efficacy and resistance development in key bacterial species. Biomedical Physics \& Engineering Express. 2018Nov;5(1):015013. https://doi.org/10.1088/20571976/aad5a7

[11] Qing Y, Cheng L, Li R, Liu G, Zhang Y, Tang X, et al. Potential antibacterial mechanism of silver nanoparticles and the optimization of orthopedic implants by advanced modification technologies. International Journal of Nanomedicine. 2018Jun;13:3311-27. https://doi.org/ 10.2147/IJN.S165125

[12] Smith JN, Thomas DG, Jolley H, Kodali VK, Littke $\mathrm{MH}$, Munusamy $\mathrm{P}$, et al. All that is silver is not toxic: silver ion and particle kinetics reveals the role of silver ion aging and dosimetry on the toxicity of silver nanoparticles. Particle and Fibre Toxicology. 2018Dec;15(1). https://doi.org/10.1186/s12989-0180283-Z

Leong et al. | URNCST Journal (2020): Volume 4, Issue 9

DOI Link: https://doi.org/10.26685/urnest.198
[13] Anderson D, Patchin E, Silva R, Uyeminami D, Sharmah A, Guo T et al. Influence of Particle Size on Persistence and Clearance of Aerosolized Silver Nanoparticles in the Rat Lung. Toxicological Sciences. 2015Jan;144(2):366-381. https://doi.org/10.1093/toxsci/ kfv005

[14]Barros SM, Whitaker SK, Sukthankar P, Avila LA, Gudlur S, Warner $M$, et al. A review of solute encapsulating nanoparticles used as delivery systems with emphasis on branched amphipathic peptide capsules. Archives of Biochemistry and Biophysics. 2016Feb;596:22-42. https://doi.org/10.1016/j.abb.2016 .02 .027

[15] Technology: What is BAPC'M (Branched Amphipathic Peptide Capsules) [Internet]. Phoreus Biotech. [cited 2020Jul22]. Available from: https://www phoreusbiotech.com/technology/

[16] Sukthankar P, Avila L, Whitaker S, Iwamoto T, Morgenstern A, Apostolidis $\mathrm{C}$ et al. Branched amphiphilic peptide capsules: Cellular uptake and retention of encapsulated solutes. Biochimica et Biophysica Acta (BBA) - Biomembranes. 2014Sep; 1838(9):2296-2305. https://doi.org/10.1016/j.bbamem .2014 .02 .005

[17] Riaz M, Riaz M, Zhang X, Lin C, Wong K, Chen X, et al. Surface Functionalization and Targeting Strategies of Liposomes in Solid Tumor Therapy: A Review. International Journal of Molecular Sciences. 2018Jan;19(1):195. $\quad$ https://doi.org/10.3390/ijms 19010195

[18] Conroy BS, Grigg JC, Kolesnikov M, Morales LD, Murphy MEP. Staphylococcus aureus heme and siderophore-iron acquisition pathways. BioMetals. 2019Jun;32(3):409-24. https://doi.org/10.1007/s10534019-00188-2

[19] Haley KP, Skaar EP. A battle for iron: host sequestration and Staphylococcus aureus acquisition. Microbes and Infection. 2011Nov;14(3):217-27. https://doi.org/10.1016/j.micinf.2011.11.001

[20] Zhao N, Enns CA. Iron Transport Machinery of Human Cells. Metal Transporters Current Topics in Membranes. 2012Dec;69:67-93. https://doi.org/10.1016/B978-0-12394390-3.00003-3

[21] Wilson BR, Bogdan AR, Miyazawa M, Hashimoto K, Tsuji Y. Siderophores in Iron Metabolism: From Mechanism to Therapy Potential. Trends in Molecular Medicine. 2016Nov;22(12):1077-90. https://doi.org/ 10.1016/j.molmed.2016.10.005

[22] Bélteky P, Rónavári A, Igaz N, Szerencsés B, Tóth IY, Pfeiffer I, et al. Silver nanoparticles: aggregation behavior in biorelevant conditions and its impact on biological activity. International Journal of Nanomedicine. 2019Jan;14:667-87. https://doi.org/ 10.2147/IJN.S185965

[23] Ferdous Z, Nemmar A. Health Impact of Silver Nanoparticles: A Review of the Biodistribution and 
UNDERGRADUATE RESEARCH IN NATURAL AND CLINICAL SCIENCE AND TECHNOLOGY (URNCST) JOURNAL

Read more URNCST Journal articles and submit your own today at: https://www.urncst.com

Toxicity Following Various Routes of Exposure. International Journal of Molecular Sciences.

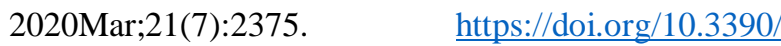
ijms21072375

[24] Qing Y, Cheng L, Li R, Liu G, Zhang Y, Tang X et al. Potential antibacterial mechanism of silver nanoparticles and the optimization of orthopedic implants by advanced modification technologies. International Journal of Nanomedicine. 2018Jun;13:3311-3327. https://doi.org/10.2147/IJN. $\underline{\mathrm{S} 165125}$

[25] Barros SD, Avila LA, Whitaker SK, Wilkinson KE, Sukthankar P, Beltrão EI, Tomich JM. Branched Amphipathic Peptide Capsules: Different Ratios of the Two Constituent Peptides Direct Distinct Bilayer Structures, Sizes, and DNA Transfection Efficiency. Langmuir. 2017Jun;33(28):7096-104. https://doi.org/10.1021/acs.langmuir.7b00912

[26] Lower BH, Lins RD, Oestreicher Z, Straatsma TP, Hochella MF, Shi L, et al. In Vitro Evolution of a Peptide with a Hematite Binding Motif That May Constitute a Natural Metal-Oxide Binding Archetype. Environmental Science \& Technology. 2008Apr;42(10):3821-7. https://doi.org/10.1021/es702688c

[27] Naqvi SZ, Kiran U, Ali, Jamal, Hameed, Ahmed, et al. Combined efficacy of biologically synthesized silver nanoparticles and different antibiotics against multidrug-resistant bacteria. International Journal of Nanomedicine. 2013Aug;8(1):3187-95. https://doi.org/ 10.2147/ijn.s49284

[28] Vitko NP, Richardson AR. Laboratory maintenance of methicillin-resistant Staphylococcus aureus (MRSA). Current Protocols in Microbiology. 2013Feb;28(1): 9C.2.1-9C.2.14. https://doi.org/10.1002/9780471729259. $\mathrm{mc09c02s28}$

[29] Barratt G, Patravale V, Poon K, Silva A. Drug Delivery Vehicle [Internet]. Drug Delivery Vehicle - an overview | ScienceDirect Topics. 2018 [cited 2019Nov20]. Available from: https://www.sciencedirect.com/ topics/medicine-and-dentistry/drug-delivery-vehicle

[30] Qais F, Shafiq A, Khan H, Husain F, Khan R, Alenazi B et al. Antibacterial Effect of Silver Nanoparticles Synthesized Using Murraya koenigii (L.) against Multidrug-Resistant Pathogens. Bioinorganic Chemistry and Applications. 2019Jul;2019:1-11. https://doi.org/10.1155/2019/4649506

[31] Johari S, Mohtar M, Syed Mohamad S, Mohammat M, Sahdan R, Mohamed A et al. In Vitro Evaluations and In Vivo Toxicity and Efficacy Studies of MFM501 against MRSA. BioMed Research International. 2017Apr;2017:1-10. $\quad$ https://doi.org/10.1155/2017/ 8032865

[32] Dudley JT, Butte AJ. Identification Of Discriminating Biomarkers For Human Disease Using Integrative Network Biology. Biocomputing 2009. 2008;2:27-38. https://doi.org/10.1142/9789812836939 0004

Leong et al. | URNCST Journal (2020): Volume 4, Issue 9 DOI Link: https://doi.org/10.26685/urncst.198
[33] Cao M, Feng Y, Zhang Y, Kang W, Lian K, Ai L. Studies on the metabolism and degradation of vancomycin in simulated in vitro and aquatic environment by UHPLC-Triple-TOF-MS/MS. Scientific Reports. 20180ct;8(1):1-3. $\quad$ https://doi.org/10.1038/ s41598-018-33826-9

[34] Slama TG, Amin A, Brunton SA, File Jr TM, Milkovich G, Rodvold KA, Sahm DF, Varon J, Weiland Jr D. A clinician's guide to the appropriate and accurate use of antibiotics: the Council for Appropriate and Rational Antibiotic Therapy (CARAT) criteria. 2005Jul;118(7): 1-6. https://doi.org/10.1016/j.amjmed.2005.05.007

[35] Tang J, Hu J, Kang L, Deng Z, Wu J, Pan J. The use of vancomycin in the treatment of adult patients with methicillin-resistant Staphylococcus aureus (MRSA) infection: a survey in a tertiary hospital in China. International Journal of Clinical and Experimental Medicine. 2015;8(10):19436-19441.

[36] Sakoulas G, Moise-Broder PA, Schentag J, Forrest A, Moellering RC, Eliopoulos GM. Relationship of MIC and Bactericidal Activity to Efficacy of Vancomycin for Treatment of Methicillin-Resistant Staphylococcus aureus Bacteremia. Journal of Clinical Microbiology. 2004Jun;42(6):2398-402. https://doi.org/10.1128/JCM 42.6.2398-2402.2004

[37] National Nosocomial Infections Surveillance (NNIS) Report, data summary from October 1986-April 1996, issued May 1996. American Journal of Infection Control. 1996Oct;24(5):380-8. https://doi.org/10.1016/ S0196-6553(96)90026-7

[38] Park E-J, Bae E, Yi J, Kim Y, Choi K, Lee SH, et al. Repeated-dose toxicity and inflammatory responses in mice by oral administration of silver nanoparticles. Environmental Toxicology and Pharmacology. 2010Sep;30(2):162-8. https://doi.org/10.1016/j.etap.2010 .05 .004

[39] Tiwari DK, Jin T, Behari J. Dose-dependent in-vivo toxicity assessment of silver nanoparticle in Wistar rats. Toxicology Mechanisms and Methods. 2010Nov;21(1):13-24. https://doi.org/10.3109/ $\underline{15376516.2010 .529184}$

[40] Rai M, Deshmukh S, Ingle A, Gade A. Silver nanoparticles: the powerful nanoweapon against multidrug-resistant bacteria. Journal of Applied Microbiology. 2012Feb;112(5):841-52. https://doi.org/10 $.1111 / \mathrm{j} .1365-2672.2012 .05253 . \mathrm{x}$

[41] Hammer N, Skaar E. Molecular Mechanisms of Staphylococcus aureus Iron Acquisition. Annual Review of Microbiology. 20110ct;65(1): 129-147. $\quad$ https://doi.org/10.1146/annurev-micro090110-102851

[42] Stauff D, Skaar E. The Heme Sensor System of Staphylococcus aureus. Contributions to Microbiology. 2009Jun;16:120-135. https://doi.org/10.1159/000219376 
UNDERGRADUATE RESEARCH IN NATURAL AND CLINICAL SCIENCE AND TECHNOLOGY (URNCST) JOURNAL Read more URNCST Journal articles and submit your own today at: https://www.urncst.com

\author{
Article Information \\ Managing Editor: Jeremy Y. Ng \\ Peer Reviewers: Madison Best, Jordan Donders \\ Article Dates: Received Jul 22 20; Accepted Sep 17 20; Published Oct 0520
}

\title{
Citation
}

Please cite this article as follows:

Lee J, Leong R, Chen Z, Zhang C. Potential application of silver nanoparticles encapsulated in branched amphiphilic peptide capsules to circumvent antibiotic resistance in methicillin-resistant Staphylococcus Aureus: A research protocol. URNCST Journal. 2020 Oct 05: 4(9). https://urncst.com/index.php/urncst/article/view/198

DOI Link: https://doi.org/10.26685/urncst.198

\section{Copyright}

(C) Joan Lee, Russell Leong, Zejia Chen, Chelsea Zhang. (2020). Published first in the Undergraduate Research in Natural and Clinical Science and Technology (URNCST) Journal. This is an open access article distributed under the terms of the Creative Commons Attribution License (https://creativecommons.org/licenses/by/4.0/), which permits unrestricted use, distribution, and reproduction in any medium, provided the original work, first published in the Undergraduate Research in Natural and Clinical Science and Technology (URNCST) Journal, is properly cited. The complete bibliographic information, a link to the original publication on http://www.urncst.com, as well as this copyright and license information must be included.
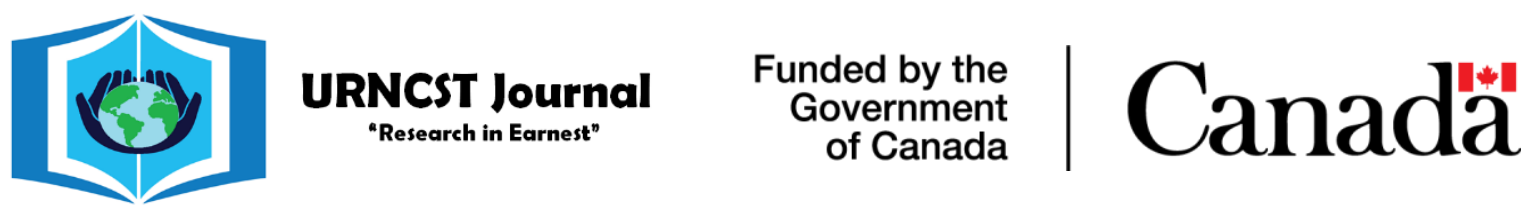

Do you research in earnest? Submit your next undergraduate research article to the URNCST Journal!

|Open Access | Peer-Reviewed | Rapid Turnaround Time | International |

| Broad and Multidisciplinary | Indexed | Innovative | Social Media Promoted |

Pre-submission inquiries? Send us an email at info@ urncst.com | Facebook, Twitter and LinkedIn: @ URNCST

Submit YOUR manuscript today at https://www.urncst.com! 